\title{
Control de convencionalidad: precisiones para su aplicación desde la jurisprudencia de la Corte Interamericana de Derechos Humanos
}

Este artículo se encuentra disponible para su descarga gratuita en www.anuariocdh.uchile.cl

\begin{abstract}
Juana María Ibáñez Rivas
Abogada de la Pontificia Universidad Católica del Perú. Consultora en temas de derecho internacional de los derechos humanos, derecho internacional humanitario y justicia transicional. Previamente, trabajó como abogada del Área Legal en la Corte Interamericana de Derechos Humanos y anteriormente como asesora jurídica de la Delegación Regional del Comité Internacional de la Cruz Roja (CICR) para Bolivia, Ecuador y Perú.

ibanez.jm@pucp.edu.pe
\end{abstract}

\section{RESUMEN}

El "control de convencionalidad" establecido a partir de 2006 en la jurisprudencia de la Corte Interamericana de Derechos Humanos ha sido objeto de importantes precisiones. En sus sentencias de finales de 2010 y principios de 2011, el Tribunal ha puntualizado cuáles son los actores estatales obligados a su aplicación, la necesidad de su ejercicio sobre las decisiones mayoritarias en contextos democráticos y la verificación que la Corte puede realizar sobre el control de convencionalidad que alegan haber ejercido los Estados a nivel interno. En este sentido, el presente artículo hace un recorrido por el origen, evolución y aplicación del denominado "control de convencionalidad", como medida orientada al cumplimiento de las obligaciones estatales de respeto, garantía y adecuación contempladas en la Convención Americana sobre Derechos Humanos.

Palabras clave: Control de convencionalidad - Control de constitucionalidad - Obligaciones de respeto, garantía y adecuación - Corte Interamericana de Derechos Humanos

\section{SUMMARY}

The "conventionality control" established in 2006 in the case law of the Inter-American Court of Human Rights has undergone some important clarifications. In its rulings from the end of 2010 and the beginning of 2011, the Court has defined the state actors that are obligated to apply it, has established the need for it when dealing with majoritarian decisions in democratic contexts and has established the role of the Court in verifying the conventionality control that States claim to have exercised domestically. This article covers the origin, evolution and application of the so-called "conventionality control" as a measure designed to assure compliance with the state obligations to respect, ensure and conform domestic legislation to international law, which are all found in the American Convention on Human Rights.

Key words: Conventionality control - Control of constitutionality - Obligations to respect, ensure and conform - Inter-American Court of Human Rights

\section{Introducción}

De acuerdo con la teoría del desdoblamiento funcional de Scelle, los Estados son creadores y destinatarios del derecho internacional. Al no existir en el ordenamiento internacional órganos centralizados y superiores a los Estados que controlen la aplicación de sus normas, queda a estos ser los principales responsables de la aplicación del derecho internacional ${ }^{1}$.

SCELLE, Georges. Citado en: SALMÓN, Elizabeth. Introducción al Derecho Internacional Humanitario. Lima: Fondo Editorial PUCP, 2004, p. 35. 
Si bien el derecho internacional no obliga a los Estados a reconocer la primacía de las normas internacionales al interior de su ordenamiento jurídico interno, el artículo 27 de la Convención de Viena sobre el Derecho de los Tratados de 1969 sí establece que un Estado Parte no podrá invocar las disposiciones de su derecho interno como justificación para el incumplimiento de un tratado. La necesidad de cumplir lo dispuesto en un tratado respecto del cual un Estado consintió implica que éste debe aplicar e implementar el derecho internacional que corresponda en su derecho interno mediante la creación de normas o toma de medidas que se ajusten al compromiso asumido y la derogación de aquellas incompatibles con ese compromiso.

A partir de ello, el presente artículo desarrolla el origen, evolución y exigencias de aplicación del denominado "control de convencionalidad", como medida orientada al cumplimiento de las obligaciones estatales de respeto, garantía y adecuación contempladas en la Convención Americana sobre Derechos Humanos ("Convención Americana" o "Convención"). Dicha figura, establecida a partir de 2006 en la jurisprudencia de la Corte Interamericana de Derechos Humanos ("Corte Interamericana", "Corte IDH", "Corte", o "Tribunal"), ha sido objeto de importantes precisiones, siendo especialmente relevantes las de finales de 2010 e inicios de 2011, cuando el Tribunal se refirió a los actores estatales obligados a su aplicación, a la necesidad de su ejercicio sobre las decisiones mayoritarias en contextos democráticos y a la verificación que la Corte puede realizar sobre el control de convencionalidad que alegan haber ejercido los Estados a nivel interno.

Sobre la base de ello, el presente artículo se estructura en tres capítulos. El primero se refiere al contenido de las obligaciones de respeto, garantía y adecuación en la jurisprudencia del Tribunal; el segundo, al "control de convencionalidad" entendido como una manifestación de dichas obligaciones estatales; el tercero, a la competencia de la propia Corte Interamericana en la verificación de la aplicación del "control de convencionalidad" por parte de los Estados y se finaliza con algunas consideraciones a modo de conclusión.

\section{Las obligaciones de respeto, garantía y adecuación en el sistema interamericano de derechos humanos}

El artículo 1.1 de la Convención Americana ${ }^{2}$ obliga a los Estados Parte a respetar y garantizar, sin discriminación alguna, el libre y pleno ejercicio de los derechos y libertades contenidos en ella. En ese sentido, desde la sentencia en el caso Velásquez Rodríguez respecto del Estado de Honduras, el Tribunal ha afirmado que, conforme al artículo 1.1, "todo menoscabo a los derechos humanos reconocidos en la Convención que pueda ser atribuido, según las reglas del Derecho internacional, a la acción u omisión de cualquier autoridad pública, constituye un hecho imputable al Estado que compromete su responsabilidad en los términos previstos por la misma Convención" ${ }^{3}$.

Las obligaciones de respeto y garantía derivadas del artículo 1.1 se complementan con el contenido del artículo 2 de la Convención ${ }^{4}$, el cual alude al deber estatal de adoptar disposiciones de

2 El artículo 1.1 de la Convención establece que "[l]os Estados Partes en [la] Convención se comprometen a respetar los derechos y libertades reconocidos en ella y a garantizar su libre y pleno ejercicio a toda persona que esté sujeta a su jurisdicción, sin discriminación alguna por motivos de raza, color, sexo, idioma, religión, opiniones jurídicas o de cualquier otra índole, origen nacional o social, posición económica, nacimiento o cualquier otra condición social".

3 Corte IDH. Caso Velásquez Rodríguez vs. Honduras. Fondo. Sentencia de 29 de julio de 1988. Serie C No. 4, párrs. 164 a 177.

4 El artículo 2 de la Convención establece que "[s]i el ejercicio de los derechos y libertades mencionados en el Artículo 1 no estuviere ya garantizado por disposiciones legislativas o de otro carácter, los Estados Partes se comprometen a adoptar, con arreglo a sus procedimientos constitucionales y a las disposiciones de [la] Convención, las medidas legislativas o de otro carácter que fueren necesarias para hacer efectivos tales derechos y libertades". La fuente del citado artículo 2 de la Convención es el artículo 2.2 del Pacto Internacional de Derechos Civiles y Políticos. La Convención Europea 
derecho interno para hacer efectivos los derechos y libertades reconocidos en dicho tratado. Este artículo 2 "no define cuáles son las medidas pertinentes para la adecuación del derecho interno a la [Convención], obviamente por depender ello del carácter de la norma que la requiera y las circunstancias de la situación concreta". Sin embargo, la Corte ha interpretado que tal adecuación implica la adopción de medidas en dos vertientes: (i) la supresión de las normas y prácticas de cualquier naturaleza que entrañen violación a las garantías previstas en la Convención o que desconozcan los derechos allí reconocidos u obstaculicen su ejercicio y (ii) la expedición de normas y el desarrollo de prácticas conducentes a la efectiva observancia de dichas garantías 5 .

En ese sentido, el cumplimiento de las obligaciones de respeto, garantía y adecuación en el sistema interamericano exige además de la organización de un aparato estatal conforme a las normas de derechos humanos, una conducta gubernamental que asegure el eficaz funcionamiento de dicha estructura. Siguiendo la jurisprudencia de la Corte Interamericana, si un Estado manifiesta su intención de cumplir con la Convención Americana, la no derogación de una norma incompatible con ésta y la falta de adaptación de las normas y comportamientos internos por parte de los poderes Legislativo y Judicial para hacer efectivas dichas normas, determinan que el Estado viole dicho tratado ${ }^{6}$. El hecho de que se trate de leyes internas y de que éstas hayan sido adoptadas de acuerdo con lo dispuesto por la Constitución nacional, nada justifica si mediante ellas se violan cualquiera de los derechos o libertades protegidos por la Convención ${ }^{7}$.

Por todo lo expuesto, a partir de los deberes generales establecidos en los artículos 1.1 y 2, los Estados Parte están obligados a armonizar su ordenamiento jurídico interno con la normativa de protección de la Convención. Una importante herramienta para contribuir a dicho fin es el denominado "control de convencionalidad", pues éste "puede en mucho contribuir a asegurar que [la Convención Americana] genere sus efectos propios (effet utile) en el derecho interno de los Estados Partes ${ }^{\prime 8}$.

\section{El control de convencionalidad en la jurisprudencia de la Corte Interamericana como mani- festación de las obligaciones estatales de respeto, garantía y adecuación}

Teniendo en cuenta las exigencias propias de las obligaciones estatales de respeto, garantía y adecuación, a través del denominado "control de convencionalidad" la Corte ha hecho notar a los Estados que, independientemente de las reformas legales que deban adoptar para compatibilizar determinadas disposiciones y prácticas con la Convención Americana y los estándares internacionales que correspondan, en principio, los jueces y órganos vinculados a la administración de

para la Salvaguardia de los Derechos del Hombre y de las Libertades Fundamentales no contiene una disposición análoga, no obstante, su artículo 1 tiene como efecto que los Estados Parte de aquélla -y de sus respectivos Protocolos Adicionales- cumplan una doble obligación: en primer lugar, asegurar que su derecho interno sea compatible con la Convención; y en segundo lugar, subsanar todo desconocimiento de los derechos y libertades protegidos por ella. Cfr. CARRILlO SALCEDO, Juan Antonio. "Artículo 1". En: PETTITI, Louis et. al. La Convention Européenne des Droits de I'homme. Commentaire article par article. Paris: Economica, 1995, pp. 135-141. Por su parte, la Carta Africana sobre los Derechos Humanos y de los Pueblos alude en sus artículos 1 y 25 a las medidas que deben adoptar los Estados miembros de la Organización para la Unidad Africana para hacer efectivos los derechos, deberes y libertades contemplados en dicha Carta.

5 Corte IDH. Caso Castillo Petruzzi y otros vs. Perú. Fondo, Reparaciones y Costas. Sentencia de 30 de mayo de 1999. Serie C No. 52, párr. 207.

6 Corte IDH. Caso Suárez Rosero vs. Ecuador. Fondo. Sentencia de 12 de noviembre de 1997. Serie C No. 35, párr. 98.

7 Corte IDH. Ciertas Atribuciones de la Comisión Interamericana de Derechos Humanos (arts. 41, 42, 44, 46, 47, 50 y 51 Convención Americana sobre Derechos Humanos). Opinión Consultiva OC-13/93 del 16 de julio de 1993. Serie A No. 13, párr. 27.

8 Voto disidente del juez Antonio Cançado Trindade, párr. 45. Corte IDH. Caso Trabajadores Cesados del Congreso (Aguado Alfaro y otros) vs. Perú. Solicitud de Interpretación de la Sentencia de Excepciones Preliminares, Fondo, Reparaciones y Costas. Sentencia de 30 de noviembre de 2007. Serie C No. 174. 
justicia en todos los niveles deben actuar inmediatamente y de oficio en el sentido de adecuar sus decisiones a dichas disposiciones y estándares, frente al conocimiento de los casos que se les sometan.

El contenido del "control de convencionalidad" en la jurisprudencia del Tribunal ha sido objeto de un proceso de evolución que ha precisado sus alcances, con miras a asegurar y facilitar su aplicación por parte de los Estados.

\subsection{El origen del concepto de "control de convencionalidad"}

En el año 2006, al resolver el caso Almonacid Arellano y otros respecto del Estado de Chile, el Tribunal declaró que el Poder Judicial chileno aplicó una norma que tuvo como efecto el cese de las investigaciones y el archivo del expediente de la ejecución extrajudicial del señor Almonacid Arellano, dejando en la impunidad a los responsables. En dicha oportunidad, la Corte Interamericana consideró el supuesto en el cual "el [Poder] Legislativo falla en su tarea de suprimir y/o no adoptar leyes contrarias a la Convención Americana", frente a lo cual "el [Poder] Judicial permanece vinculado al deber de garantía establecido en el artículo 1.1 de la misma y, consecuentemente, debe abstenerse de aplicar cualquier normativa contraria a ella" ${ }^{\prime 9}$.

Si bien la Corte declaró "[ser] consciente que los jueces y tribunales internos están sujetos al imperio de la ley y, por ello, [...] obligados a aplicar las disposiciones vigentes en el ordenamiento jurídico", recordó que "cuando un Estado ha ratificado un tratado internacional como la Convención Americana, sus jueces, como parte del aparato del Estado, también están sometidos a ella, lo que les obliga a velar porque los efectos de las disposiciones de la Convención no se vean mermad[o]s por la aplicación de leyes contrarias a su objeto y fin, y que desde un inicio carecen de efectos jurídicos". Para ello, el Tribunal indicó que el Poder Judicial debe ejercer "una especie" de "control de convencionalidad" entre las normas jurídicas internas que aplican en los casos concretos y la Convención Americana ${ }^{10}$.

Aunado a ello, el Tribunal estableció que "el Poder Judicial debe tener en cuenta no solamente el tratado, sino también la interpretación que del mismo ha hecho la Corte Interamericana, intérprete última de la Convención Americana"11. Como fundamento de tal afirmación, la Corte citó su Opinión Consultiva sobre la Responsabilidad Internacional por Expedición y Aplicación

9 Corte IDH. Caso Almonacid Arellano y otros vs. Chile. Excepciones Preliminares, Fondo, Reparaciones y Costas. Sentencia de 26 de septiembre de 2006. Serie C No. 154, párr. 123.

10 A pesar de que la sentencia en el caso Almonacid Arellano y otros fue la primera en la que la Corte se refirió al "control de convencionalidad" strictu sensu, este concepto ya había iniciado su desarrollo en la jurisprudencia del Tribunal. En efecto, conforme lo señala Ferrer Mac-Gregor, si se observa con detenimiento fallos previos "puede apreciarse que algunos de los criterios fueron adoptados con anterioridad a la creación pretoriana del 'control de convencionalidad' en dicho caso". Así, "[r]esulta evidente que la Corte [...] crea la doctrina del 'control difuso de convencionalidad' advirtiendo la tendencia de la 'constitucionalización' o, si se prefiere, 'nacionalización' del 'derecho internacional de los derechos humanos' y particularmente la aceptación de su jurisprudencia convencional como elemento 'hermenéutico' y de 'control' de la normatividad interna por parte de los propios tribunales internos". Voto razonado del juez ad hoc Eduardo Ferrer Mac-Gregor Poisot, párr. 29. Corte IDH. Caso Cabrera García y Montiel Flores vs. México. Excepción Preliminar, Fondo, Reparaciones y Costas. Sentencia de 26 de noviembre de 2010. Serie C No. 220. Al respecto, la doctrina se remite a los votos concurrentes del juez Sergio García Ramírez en las sentencias de los casos Myrna Mack Chang vs. Guatemala de 25 de noviembre de 2003; Tibi vs. Ecuador de 7 de septiembre de 2004, y López Álvarez vs. Honduras de 1 de febrero de 2006. Ver en el mismo sentido, HITTERS, Juan Carlos. "Control de constitucionalidad y control de convencionalidad. Comparación (Criterios fijados por la Corte Interamericana de Derechos Humanos)". Revista Estudios Constitucionales Vol. 7, 2009 (2), pp. 109-128.

11 Corte IDH. Caso Almonacid Arellano y otros, op. cit., párr. 124. 
de Leyes Violatorias de la Convención, recordando lo dispuesto por el ya citado artículo 27 de la Convención de Viena sobre el Derecho de los Tratados de $1969^{12}$.

Casi dos meses después, en el caso Trabajadores Cesados del Congreso (Aguado Alfaro y otros) respecto del Perú13, la Corte enfatizó que los órganos del Poder Judicial deben ejercer ya no "un cierto" control conforme se indicó en Almonacid Arellano y otros, sino un control "de convencionalidad". En este ejercicio de precisión del concepto, la Corte Interamericana se refirió a algunas características específicas de dicho control:

i) es de aplicación ex officio por parte de los órganos del Poder Judicial, "evidentemente en el marco de sus respectivas competencias y de las regulaciones procesales correspondientes". En ese sentido, "[e]sta función no debe quedar limitada exclusivamente por las manifestaciones o actos de los accionantes en cada caso concreto, aunque tampoco implica que ese control deba ejercerse siempre, sin considerar otros presupuestos formales y materiales de admisibilidad y procedencia de ese tipo de acciones";

ii) es complementario al "control de constitucionalidad", de manera que se debe aplicar además del citado control al que están obligados los órganos del Poder Judicial por su propia legislación interna y;

iii) es de aplicación también en un eventual "contexto de impedimentos normativos y prácticos para asegurar un acceso real a la justicia y de una situación generalizada de ausencia de garantías e ineficacia de las instituciones judiciales"14.

En su voto razonado a dicha sentencia, el entonces juez del Tribunal, Sergio García Ramírez, señaló que si bien en el caso concreto la Corte se refirió al "control de convencionalidad" "teni[endo] a la vista la aplicabilidad y aplicación de la Convención Americana", "la misma función se despliega, por idénticas razones, en lo que toca a otros instrumentos de igual naturaleza, integrantes del corpus juris convencional de los derechos humanos de los que es parte el Estado", citando a modo de ejemplo, el Protocolo de San Salvador, el Protocolo relativo a la Abolición de la Pena de Muerte, la Convención para Prevenir y Sancionar la Tortura, la Convención de Belém do Pará para la Erradicación de la Violencia contra la Mujer y la Convención sobre Desaparición Forzada. Conforme lo señaló García Ramírez "[d]e lo que se trata es de que haya conformidad entre los actos internos y los compromisos internacionales contraídos por el Estado, que generan para éste determinados deberes y reconocen a los individuos ciertos derechos ${ }^{\prime 15}$.

12 Corte IDH. Responsabilidad Internacional por Expedición y Aplicación de Leyes Violatorias de la Convención (Arts. 1 y 2 Convención Americana Sobre Derechos Humanos). Opinión Consultiva OC-14/94 del 9 de diciembre de 1994, Serie A No. 14, párr. 35.

13 Corte IDH. Caso Trabajadores Cesados del Congreso (Aguado Alfaro y otros) vs. Perú. Excepciones Preliminares, Fondo, Reparaciones y Costas. Sentencia de 24 de Noviembre de 2006. Serie C No. 158.

14 Corte IDH. Caso Trabajadores Cesados del Congreso, op. cit., párrs. 128 y 129.

15 Voto razonado del juez Sergio García Ramírez, párr. 2. Corte IDH. Caso Trabajadores Cesados del Congreso, op. cit. Al respecto, Néstor Sagüés ha señalado que "[q]ueda la incógnita de determinar si en verdad la Corte Interamericana ha querido conscientemente proyectar la teoría del control de convencionalidad a cualquier tratado". Para dicho autor "[e] s un punto que merece en el futuro de una pronta y clara explicitación por parte de [la] Corte, ya que involucra temas tales como si todos los tratados de derechos humanos tienen para los países ratificantes del Pacto de San José de Costa Rica rango supraconstitucional, y si es obligación -o no- de todos los jueces del área inaplicar, incluso de oficio, las reglas locales que lo contradigan". SAGÜÉS, Néstor. "Obligaciones internacionales y control de convencionalidad". Revista Estudios Constitucionales Vol. 8, 2010 (1), pp. 126-127. 
En el mismo mes de noviembre de 2006, en la sentencia del caso La Cantuta, también respecto del Estado del Perú16, el Tribunal reiteró los estándares fijados hasta el momento sobre "control de convencionalidad" en las sentencias de los casos Almonacid Arellano y otros y Trabajadores Cesados del Congreso. Con ocasión a dicho caso, referido a la ejecución extrajudicial de nueve estudiantes y un profesor de la Universidad La Cantuta, en "un contexto de práctica sistemática de detenciones ilegales y arbitrarias, torturas, ejecuciones extrajudiciales y desapariciones forzadas, perpetrada por las fuerzas de seguridad e inteligencia estatales" y en el que se emitieron leyes de autoamnistía, el juez García Ramírez, en su voto concurrente, señaló que "[n]o tendría sentido afirmar la "anticonvencionalidad" de la norma en una hipótesis particular y dejar incólume la fuente de violación para los casos que se presenten en el futuro", ya que "[l]ejos de establecer una garantía de no repetición [...], se estaría abriendo la puerta a la reiteración de la violación". En esa línea, concluyó que "[s] ería impracticable -y frustrante- requerir nuevos pronunciamientos de la Corte Interamericana que abarquen y resuelvan una serie indefinida de casos de la misma naturaleza, Ilevados a la consideración de aquélla, uno a uno, con el propósito de obtener la respectiva declaratoria de "anticonvencionalidad"17.

El "control de convencionalidad" es definido entonces como una herramienta jurídica de aplicación obligatoria ex officio por los órganos del Poder Judicial, complementaria al control de constitucionalidad, que permite garantizar que la actuación de dichos órganos resulte conforme a las obligaciones contraídas por el Estado respecto del tratado del cual es parte.

\subsection{Evolución del "control de convencionalidad" en la jurisprudencia del Tribunal}

La jurisprudencia así descrita fue reiterada al año siguiente, en 2007, en la sentencia del caso Boyce y otros respecto del Estado de Barbados ${ }^{18}$. En 2008, los estándares sobre "control de convencionalidad" fueron citados únicamente en la sentencia del caso Heliodoro Portugal respecto de Panamá19. En 2009, la Corte también reiteró su jurisprudencia sobre la materia en la sentencia del caso Rosendo Radilla Pacheco respecto de México ${ }^{20}$. En 2010, dicho concepto fue desarroIlado en ocho sentencias: Manuel Cepeda Vargas respecto de Colombia ${ }^{21}$; Comunidad Indígena Xákmok Kásek respecto de Paraguay ${ }^{22}$; Fernández Ortega y Otros respecto de México ${ }^{23}$; Rosendo

16 Corte IDH. Caso La Cantuta vs. Perú. Fondo, Reparaciones y Costas. Sentencia de 29 de noviembre de 2006. Serie C No. 162.

17 Voto razonado del juez Sergio García Ramírez, párr. 7. Corte IDH. Caso La Cantuta, op. cit. Dicha postura ha generado pronunciamientos en la doctrina que ponen en debate tal posibilidad dentro del sistema interamericano. Nestor Sagüés señala que "[e]l tribunal ha agregado algo al contenido inicial del Pacto, aunque el texto literal de éste no ha variado. Así, un Estado puede verse obligado por la doctrina sentada por la Corte Interamericana de Derechos Humanos, en una causa en la que él no ha sido parte, ni obviamente tenido oportunidad para alegar en pro de una interpretación diferente a la formulada en aquel expediente". SAGÜÉS, Néstor. "Obligaciones internacionales...", op. cit., pp. 125-126. Ver también: RUIZ CHIRIBOGA, Oswaldo. "The Conventionality Control: Examples of (un)successful experiences in Latin America". Inter-American and European Human Rights Journal Vol. 3, No. 1-2, 2010, pp. 203-204.

18 Corte IDH. Caso Boyce y otros vs. Barbados. Excepción Preliminar, Fondo, Reparaciones y Costas. Sentencia de 20 de noviembre de 2007. Serie C No. 169, párr. 79.

19 Corte IDH. Caso Heliodoro Portugal vs. Panamá. Excepciones Preliminares, Fondo, Reparaciones y Costas. Sentencia de 12 de agosto de 2008. Serie C No. 186, párr. 180.

20 Corte IDH. Caso Rosendo Radilla Pacheco vs. Estados Unidos Mexicanos. Excepciones Preliminares, Fondo, Reparaciones y Costas. Sentencia de 23 de noviembre de 2009. Serie C No. 209, párr. 339.

21 Corte IDH. Caso Manuel Cepeda Vargas vs. Colombia. Excepciones Preliminares, Fondo y Reparaciones. Sentencia de 26 de mayo de 2010. Serie C No. 213, párr. 208.

22 Corte IDH. Comunidad Indígena Xákmok Kásek vs. Paraguay. Fondo, Reparaciones y Costas. Sentencia de 24 de agosto de 2010. Serie C No. 214, párr. 311.

23 Corte IDH. Caso Fernández Ortega y Otros vs. México. Excepción Preliminar, Fondo, Reparaciones y Costas. Sentencia de 30 de agosto de 2010. Serie C No. 215, párr. 234. 
Cantú y Otra respecto de México ${ }^{24}$; Ibsen Cárdenas e Ibsen Peña respecto de Bolivia ${ }^{25}$; Vélez Loor respecto de Panamá26; Gomes Lund y Otros (Guerrilha do Araguaia) respecto de Brasil27 y Cabrera García y Montiel Flores respecto de México ${ }^{28}$. En esta última sentencia, de noviembre de 2010, la Corte Interamericana realizó una precisión clave en lo que concierne a los órganos del Estado obligados a aplicar dicho control entre las normas internas y la Convención Americana.

Dado que en algunos Estados los tribunales constitucionales, por ejemplo, constituyen órganos autónomos independientes del Poder Judicial, la Corte precisó que no sólo los jueces, sino que los diferentes "órganos vinculados a la administración de justicia en todos los niveles" están en la obligación de ejercer ex officio el "control de convencionalidad"29. A mayor abundamiento, en dicha oportunidad, la Corte citó jurisprudencia de tribunales de la más alta jerarquía en la región que se han referido y han aplicado el "control de convencionalidad", sobre la base de las interpretaciones efectuadas por la Corte Interamericana, tales como la Sala Constitucional de la Corte Suprema de Justicia de Costa Rica, el Tribunal Constitucional de Bolivia, la Suprema Corte de Justicia de República Dominicana, el Tribunal Constitucional del Perú, la Corte Suprema de Justicia de la Nación de Argentina y la Corte Constitucional de Colombia ${ }^{30}$.

En 2011, los estándares sobre el "control de convencionalidad" fueron citados en cuatro sentencias en los casos Gelman respecto del Uruguay ${ }^{31}$; Chocrón Chocrón respecto de Venezuela ${ }^{32}$; López Mendoza respecto de Venezuela ${ }^{33}$ y Fontevecchia y $D^{\prime} A m i c o$ respecto de Argentina ${ }^{34}$. Entre éstas, es preciso destacar lo declarado por la Corte Interamericana en el caso Gelman, no solo en cuanto a las autoridades obligadas a ejercer el "control de convencionalidad", sino al contexto en que éste debe ser aplicado.

El caso Gelman involucraba la vigencia y aplicación en el Uruguay de la Ley No. 15.848 o Ley de Caducidad de la Pretensión Punitiva del Estado de 1986, aprobada en un régimen democrático y respaldada por la ciudadanía en dos ocasiones, que impedía la investigación y sanción de graves violaciones de derechos humanos cometidas por funcionarios militares y policiales en el marco de la dictadura militar y la Operación Cóndor. En su sentencia, la Corte señaló que la "manifiesta incompatibilidad" de dicha Ley con la Convención Americana determina que aquélla carezca de efectos jurídicos, de manera que "no pued[e] seguir representando un obstáculo para la investigación de los hechos del [...] caso y la identificación y el castigo de los responsables, ni

24 Corte IDH. Caso Rosendo Cantú y Otra vs. México. Excepción Preliminar, Fondo, Reparaciones y Costas. Sentencia de 31 de agosto de 2010. Serie C No. 216, párr. 219.

25 Corte IDH. Caso Ibsen Cárdenas e Ibsen Peña vs. Bolivia. Fondo, Reparaciones y Costas. Sentencia de 1 de septiembre de 2010. Serie C No. 217, párr. 202.

26 Corte IDH. Caso Vélez Loor vs. Panamá. Excepciones preliminares, Fondo, Reparaciones y Costas. Sentencia de 23 de noviembre de 2010. Serie C No. 218, párr. 287.

27 Corte IDH. Caso Gomes Lund y Otros (Guerrilha do Araguaia) vs. Brasil. Excepciones preliminares, Fondo, Reparaciones y Costas. Sentencia de 24 de noviembre de 2010. Serie C No. 219, párr. 106.

28 Corte IDH. Caso Cabrera García y Montiel Flores, op. cit., párrs. 225 a 233.

29 Ibídem, párr. 225.

30 Ibídem, párrs. 226 a 232.

31 Corte IDH. Caso Gelman vs. Uruguay. Fondo y Reparaciones. Sentencia de 24 de febrero de 2011. Serie C No. 221, párr. 193.

32 Corte IDH. Caso Chocrón Chocrón vs. Venezuela. Excepción Preliminar, Fondo, Reparaciones y Costas. Sentencia de 1 de julio de 2011. Serie C No. 227, párrs. 164 a 171.

33 Corte IDH. Caso López Mendoza vs. Venezuela. Fondo Reparaciones y Costas. Sentencia de 1 de septiembre de 2011. Serie C No. 233, párrs. 226 y 227.

34 Corte IDH. Caso Fontevecchia y D'Amico vs. Argentina. Fondo, Reparaciones y Costas. Sentencia de 29 de noviembre de 2011. Serie C No. 238, párr. 93. 
pued[e] tener igual o similar impacto respecto de otros casos de graves violaciones de derechos humanos consagrados en la Convención Americana que puedan haber ocurrido en el Uruguay"35.

Al respecto, y a modo de introducción al concepto de "control de convencionalidad", la Corte recordó que "[c]uando un Estado es Parte de un tratado internacional como la Convención Americana, todos sus órganos, incluidos sus jueces, están sometidos a aquél, lo cual les obliga a velar por que los efectos de las disposiciones de la Convención no se vean mermados por la aplicación de normas contrarias a su objeto y fin"36.

Esta idea según la cual "todos" los órganos de un Estado están obligados a cumplir el tratado respecto del cual éste consintió se vio especialmente reflejada en los párrafos siguientes de la sentencia, cuando la Corte señaló que "[e]l hecho de que la Ley de Caducidad haya sido aprobada en un régimen democrático y aun ratificada o respaldada por la ciudadanía en dos ocasiones no le concede, automáticamente ni por sí sola, legitimidad ante el Derecho Internacional". De acuerdo con la Corte, "[l]a participación de la ciudadanía con respecto a dicha Ley, utilizando procedimientos [constitucionales] de ejercicio directo de la democracia", como el recurso de referéndum en $1989^{37}$ y el plebiscito de $2009^{38}$, "se debe considerar, entonces, como hecho atribuible al Estado y generador, por tanto, de la responsabilidad internacional de aquél". En ese sentido, para la Corte, "[l]a sola existencia de un régimen democrático no garantiza, per se, el permanente respeto del Derecho Internacional, incluyendo al Derecho Internacional de los Derechos Humanos" ${ }^{\prime 39}$.

Es así que la Corte, tomando como referencia las propias decisiones previas de la Suprema Corte de Justicia del Uruguay sobre la aplicación de la Ley de Caducidad ${ }^{40}$, definió un nuevo aporte en cuanto a las implicancias del "control de convencionalidad", al señalar que "la existencia de un verdadero régimen democrático está determinada por sus características tanto formales como sustanciales", por lo que, particularmente en casos de graves violaciones a las normas del Derecho Internacional de los Derechos Humanos, la protección de estos constituye un límite infranqueable a la regla de las mayorías, es decir, a la esfera de lo "susceptible de ser decidido" por parte de éstas. En ese sentido, el Tribunal declaró que en "las instancias democráticas" también debe primar un "control de convencionalidad", cuya aplicación caracterizó como "función y tarea de cualquier autoridad pública y no sólo del Poder Judicial" ${ }^{41}$. Además, como parte de su fundamentación y en

35 Corte IDH. Caso Gelman, op. cit., párr. 232.

36 Ibídem, párr. 193.

37 El 16 de abril de 1989 un grupo de ciudadanos y familiares de detenidos-desaparecidos, que conformaron la "Comisión Nacional pro Referéndum contra la Ley de Caducidad de la Pretensión Punitiva del Estado" interpuso un recurso de referéndum contra dicha Ley, el cual no fue aprobado por la ciudadanía, pues solo el $42.4 \%$ de los votantes se pronunció a favor de hacer lugar al recurso. Cfr. Corte IDH. Caso Gelman, op. cit., párr. 147.

38 El 25 de octubre de 2009 se sometió a consideración de la ciudadanía, mediante el mecanismo de "iniciativa popular", un proyecto de reforma constitucional por el cual se introduciría en la Constitución una disposición especial que declararía nula la Ley, propuesta que sólo alcanzó el 47,7\% de los votos emitidos, por lo que no fue aprobada. Cfr. Corte IDH. Caso Gelman, op. cit., párr. 149.

39 Corte IDH. Caso Gelman, op. cit., párrs. 239 y 240.

40 El 19 de octubre de 2009 la Suprema Corte de Justicia dictó la sentencia No. 365 en la causa Sabalsagaray Curutchet Blanca Stela, en la que declaró la inconstitucionalidad de los artículos 1, 3 y 4 de la Ley de Caducidad y resolvió que eran inaplicables al caso concreto. Posteriormente, el 29 de octubre de 2010 dictó otro fallo en la causa "Organización de los Derechos Humanos", en el cual reiteró la jurisprudencia establecida en el caso Sabalsagaray. Cfr. Corte IDH. Caso Gelman, op. cit., párrs. 148 y 150.

41 Corte IDH. Caso Gelman, op. cit., párr. 240. Es importante mencionar que meses después de la emisión de la sentencia en este caso, mediante Ley No. 18.831 de 27 de octubre de 2011, el Senado y la Cámara de Representantes del Uruguay, reunidos en Asamblea General, "restablec[ieron] el pleno ejercicio de la pretensión punitiva del Estado para los delitos cometidos en aplicación del terrorismo de Estado hasta el $1^{\circ}$ de marzo de 1985, comprendidos en [...] la 
"diálogo jurisprudencial" con diversas altas cortes nacionales de la región, el Tribunal citó fallos en los que éstas han concluido que las leyes de amnistía sobre graves violaciones de derechos humanos son incompatibles con las obligaciones internacionales de los Estados que las emiten ${ }^{42}$.

En consecuencia, la Corte no solo estableció que debe prevalecer un "control de convencionalidad" de la propia decisión de las mayorías en contextos democráticos, sino que enfatizó la idea según la cual dicho control supera la actuación del Poder Judicial, comprometiendo de manera expresa y categórica a "cualquier autoridad pública". Por tanto, ya que los hechos del caso concreto incluían procesos de referéndum y plebiscito, la jurisprudencia de la Corte deja en evidencia que el "control de convencionalidad" compromete a las autoridades de los diferentes poderes del Estado y no solo a las del Poder Judicial o a todas aquéllas vinculadas a la administración de justicia.

\section{La competencia de la Corte Interamericana en la verificación de la aplicación del "control de convencionalidad" por parte de los Estados}

La Corte Interamericana realiza un permanente control de convencionalidad al momento de analizar los diferentes casos que se someten a su competencia contenciosa ${ }^{43}$. Sin embargo, cabe destacar lo ocurrido en el caso Cabrera García y Montiel Flores en el que por primera vez un Estado opuso una excepción preliminar alegando que había aplicado debidamente el "control de convencionalidad" en la jurisdicción nacional.

Efectivamente, en dicho caso, México opuso una excepción preliminar de "cuarta instancia", planteando que "la Corte no p[odía] determinar si los tribunales nacionales aplicaron correctamente el derecho interno o si el fallo emitido fue equivocado o injusto" y que sólo "debe[ría] determinar" si el proceso judicial penal "se apegó a los principios de garantía y protección judicial consagrados en la Convención Americana o si existe algún error judicial comprobable y comprobado que acredite una grave injusticia". Así, agregó que en el caso "se busca[ba] revisar lo ya decidido por los tribunales domésticos", pese a que estos habrían ejercido "efectivamente el 'control de convencionalidad' ex officio" ${ }^{\prime 44}$.

Frente a ello, la Corte recordó que si bien "no desempeña funciones de tribunal de 'cuarta instancia'", sí le compete "verificar si en los pasos efectivamente dados a nivel interno se violaron o no obligaciones internacionales del Estado derivadas de los instrumentos interamericanos que le otorgan competencia"45. A partir de ello, el Tribunal observó "que la excepción preliminar presentada por el Estado toma[ba] como punto de partida que no ha[bía] existido ninguna violación de derechos humanos [...], cuando e[ra] precisamente ello lo que se debatir[ía] en el fondo del

Ley [de Caducidad]", "[d]ecl[arando] que, [dichos] delitos [...], son crímenes de lesa humanidad de conformidad con los tratados internacionales de los que la República es parte". Ley No. 18.831 sobre Pretensión Punitiva del Estado. Restablecimiento para los Delitos Cometidos en Aplicación del Terrorismo de Estado hasta el 1 de Marzo de 1985. Diario Oficial del Uruguay, 1 de noviembre de 2011.

42 Así, el Tribunal se remitió a la jurisprudencia de la Corte Suprema de Justicia de la Nación de Argentina; la Corte Suprema de Justicia de Chile; el Tribunal Constitucional de Perú; la Suprema Corte de Justicia de Uruguay; la Corte Suprema de Justicia de la República de Honduras; la Sala de lo Constitucional de la Corte Suprema de Justicia de El Salvador; la Corte Constitucional de Colombia, y de la Corte Suprema de Justicia de Colombia. Cfr. Corte IDH. Caso Gelman, op. cit., párrs. 215 a 224 .

43 Sagüés se ha referido a esta facultad como "control de convencionalidad en sede internacional", en oposición al "control de convencionalidad en sede nacional" que realizan los órganos estatales competentes. SAGÜÉS, Néstor. "Obligaciones internacionales...", op. cit., pp. 120-121.

44 Corte IDH. Caso Cabrera García y Montiel Flores, op. cit., párrs. 12 y 13.

45 Ibídem, párrs. 16 y 19. 
asunto"46. De esta manera, concluyó que en dicha etapa "se determinar[ía] si el presunto control de convencionalidad que alegó el Estado involucró un respeto de las obligaciones internacionales [...], a la luz de la jurisprudencia de[l] Tribunal y del derecho internacional aplicable", razón por la cual desestimó la excepción preliminar ${ }^{47}$.

Como queda en evidencia, el hecho de que un Estado alegue haber aplicado el "control de convencionalidad" en un caso concreto no constituye una excepción preliminar admisible que afecte la competencia de la Corte para pronunciarse sobre el fondo del asunto y analizar las presuntas violaciones de derechos humanos involucradas ${ }^{48}$.

\section{Conclusión}

A modo de conclusión, resulta pertinente citar a la Corte Permanente de Justicia Internacional, en cuanto a que "[s] in duda, todo convenio que engendra una obligación implica también una restricción del ejercicio de los derechos soberanos del Estado, pues imprime a este ejercicio una determinada dirección. Pero la facultad de contraer compromisos internacionales es precisamente un atributo de la soberanía del Estado"49. De esta manera, la exigencia de cumplimiento de las obligaciones asumidas por los Estados Parte de la Convención Americana no implica una transgresión a su soberanía estatal, pues ciertamente es en ejercicio de ésta que consintieron para vincularse jurídicamente con el contenido de dicho tratado, esto es, con los deberes generales de respecto, garantía y adecuación, así como con las exigencias propias de cada uno de los derechos humanos reconocidos en el mismo.

El "control de convencionalidad" constituye una de las medidas que los Estados deben poner en práctica para garantizar el effet utile de la Convención Americana y dar cumplimiento a las obligaciones estatales de respeto, garantía y adecuación. Así, mientras se mantenga una norma o práctica violatoria de la Convención o se omita crear o aplicar una conforme a la misma, el "control de convencionalidad" debe representar una respuesta para evitar que un nuevo caso resulte sometido a conocimiento del sistema interamericano o que un Estado reincida en la comisión de un acto generador de responsabilidad internacional, una vez emitida una sentencia de la Corte Interamericana que lo involucre.

Las precisiones respecto a las exigencias de la aplicación de dicho control, desarrolladas por la jurisprudencia de la Corte Interamericana desde el año 2006 hasta aquella que data de febrero de 2011, son solo muestras del esfuerzo del Tribunal por presentar una herramienta que claramente puede favorecer la protección de los derechos humanos desde los Estados y, paralelamente, afianzar el carácter subsidiario y complementario de la jurisdicción internacional.

Es positivo constatar que cada vez son más frecuentes los fallos de altas cortes nacionales que demuestran una aplicación del "control de convencionalidad" o que, en todo caso, exigen su ejercicio. Un caso ejemplar ha sido el reciente pronunciamiento del Pleno de la Suprema Corte

46 Ibídem, párr. 20.

47 Ibídem, párrs. 21 y 22.

48 Para Ferrer Mac-Gregor, las consideraciones del Tribunal frente a dicha excepción preliminar "no otorgan competencia absoluta a la Corte [...] para revisar en cualquier caso y condición la actuación de los jueces nacionales a la luz de la propia legislación interna, [...] cuestión que claramente excedería la competencia propia de esa jurisdicción internacional al sustituirse a la jurisdicción interna y violentar el carácter subsidiario y complementario esencial de aquélla". Voto razonado del juez ad hoc Eduardo Ferrer Mac-Gregor Poisot, párr. 9. Corte IDH. Caso Cabrera García y Montiel Flores, op. cit.

49 Corte Permanente de Justicia Internacional. Caso del Vapor "Wimbledon". Sentencia de 23 de junio de 1923. Serie A, No. 1.p. 22. 
de Justicia de la Nación de México, a partir del cual determinó que debía hacer una declaración acerca de la posible participación del Poder Judicial de la Federación en la ejecución de la sentencia dictada por la Corte Interamericana en el caso Rosendo Radilla Pacheco, "ante la duda que genera[ba] la inexistencia de normas legales expresas que regulen su ejecución, y la importancia que dicho caso reviste para el orden jurídico nacional". En el 2011, dicho Pleno, mediante Acuerdo del Tribunal de 14 de julio, ordenó que "[d]erivado de la sentencia de la Corte Interamericana de Derechos Humanos en el caso Rosendo Radilla", inter alia, "[l]os Jueces deberán Ilevar a cabo un Control de convencionalidad ex officio en un modelo de control difuso de constitucionalidad" y que al ejercer dicho control "[d]eberá[n] restringi[r] la interpretación del fuero militar en casos concretos". En consecuencia, el Pleno determinó que el modelo del control de constitucionalidad y convencionalidad que debe adoptarse es en el sentido de que: "1) los jueces del Poder Judicial de la Federación, al conocer de controversias constitucionales, acciones de inconstitucionalidad y de amparo, pueden declarar la invalidez de las normas que contravengan la Constitución Federal y/o los tratados internacionales que reconozcan derechos humanos; 2) los demás jueces del país, en los asuntos de su competencia, podrán desaplicar las normas que infrinjan la Constitución Federal y/o los tratados internacionales que reconozcan derechos humanos, sólo para efectos del caso concreto y sin hacer una declaración de invalidez de las disposiciones, y 3) las autoridades del país que no ejerzan funciones jurisdiccionales deben interpretar los derechos humanos de la manera que más los favorezca, sin que estén facultadas para declarar la invalidez de las normas o para desaplicarlas en los casos concretos" ${ }^{\prime \prime 0}$.

Con todo, y a pesar de estos nuevos avances que comienzan a adoptarse a nivel interno en algunos Estados, quedan aún muchos desafíos pendientes en cuanto a la implementación del control de convencionalidad por los diferentes órganos vinculados a la administración de justicia en todos los niveles y, más aún, en lo que concierne a "toda autoridad pública", tanto en situación de crisis institucional como en contextos democráticos.

Recibido: 31 octubre 2011

Aceptado: 2 febrero 2012

50 Pleno de la Suprema Corte de Justicia de la Nación (SCJN). Acuerdo del Tribunal de 14 de julio de 2011 (Expediente Varios 912/2010). México, Distrito Federal. 
